\title{
Reviewing the Concept of Green HRM (GHRM) and Its Application Practices (Green Staffing) with Suggested Research Agenda: A Review from Literature Background and Testing Construction Perspective
}

\author{
Dr. Safaa Shaban ${ }^{1}$ \\ ${ }^{1}$ Business Department, Faculty of Business Administration, Economics \& Political Science, The British \\ University in Egypt (BUE), Egypt \\ Correspondence: Dr. Safaa Shaban, Business Department, Faculty of Business Administration, Economics \& \\ Political Science, The British University in Egypt (BUE), Egypt.
}

Received: February 18, 2019

Accepted: April 16, 2019

Online Published: April 24, 2019

doi:10.5539/ibr.v12n5p86

URL: https://doi.org/10.5539/ibr.v12n5p86

\begin{abstract}
Green HRM has become one of the most critical topics in the Business world and sustainability. Many researchers and studies indicate that environmental green staffing associated strongly with the success of financial and marketplace components. The Green Human resource in green-oriented organisations plays a significant part in shaping the culture of suitability in their organisation. Shaping the practices and applications of the HR with the green view and applications will have an effect on all HR decisions and through all the activity of shareholders viewpoint. Currently, all the work gives more attention to the relationship between GHRM and organisation sustainability. GHRM help in creating, developing and implementing the strategy of sustainable business within the organisation. Although green HRM is still with ground-breaking, unclear define concept and its applications facing some difficulties. The purposes of this study in to present a full theoretical framework for GHRM practices and to test the perspective of the GHRM concept in construction companies in Egypt and the UK. The main finding is the perspective of the UK is higher than Egypt in realizing GHRM important to the organisations.
\end{abstract}

Keywords: Green HRM (GHRM), dimensions of GHRM, HR practices, sustainability, green staffing

\section{Introduction and Motivation of the Study}

A recently different organisation seeking to maximize their profits by concerning using different resources from the environment. However, they are still not linking the suitability of organisation with environmental sustainability. There are different drivers to apply the concept of green HRM within the organisation such as HR practices has been mentioned by different study one side and strategic management and leadership on the other hand( Govindarajulu and Daily, 2004).

Green Human Resources Management (GHRM) focus on carbon footprint reduction by reducing the amount of usage of paper, allying Low Carbon Technology (LCT), reduce travel petrol, and landfill unwanted materials, it is about the whole process of organisation related to the HR practices, organisation sustainability, leadership and employee behaviour( Aravamudhan, 2012). Different places and companies are greening their application and daily activity, one of the most highlighting projects in the UK is NWCKH, that aims to reduce carbon reduction and allying the Green concept in all application within the SMEs working in the construction, the project was implemented between2009 to 2012, and now in the third face.

As been mentioned in Justin Victor in 2008 that more than have of the companies they study, mentioned that most of the HR experts pointed that their organisations formal and informal policy, also they encourage their employees to become more environmentally friendly, using recycling schemes, discounting the use of furniture materials. one of the best schemes running now in the UK freecycle that targeted to donate with the furniture you not need to other people rather than send it to landfill.

Organisations to be able to economically sustain are required to work on two dimensions social and environment of the business process (Chesbrough, 2003). Green strategic management is the process which green 
environment strategy organisation required to develop (Lee, 2009). The GHRM include green environment objectives in their HR practices such as HR planning, recruitment\& selection, Training \& development, Performance management system (PMS), compensation and benefits (Muller- Carmen et al. 2016; and Renwick et al. 2008).

Applying online system for Performance Management System, training and development, employee screening it has an essential role in establishing and recognizing of the environmental improvement management system especially with big numbers of employees (big size organisations) throughout the HR practices that will implement the aspect of HRM within the organisational and environmental sustainability ( Nijhawan Geetu, 2014).

The concept of GHRM is focused on transforming regular employees to the green-oriented with behaviour employees that targeted their organisation sustainability by applying the concept of green policies, practices, and system. All activity included selection and recruitments, acquisition, training and development, PMS, reward, companions and benefits (Ford, 2012).

Green HR practices transform worthy intention and the desire aspiration to everyday HR activity and individual behaviour within the organisation and promote the green procedure embedding in the HR practices across the world. Green HR practices ( green staffing) including recruitment and selection individual with clear and good understanding of the environment concern that will develop the awareness between other individual within the same organisation to a green employment by delivering training targeted to embedding the impact and benefits of environment on orgainsational sustainability, groups and individual (Sharma and Gupta, 2009). There are many initiatives toward green staffing on the practical level, job analysis\& job design process emphases the environment issues such as identifies the person specification, and job duties within the framework of understanding of the environment experiences, testing and interviewing people of fit with the environment perspective of the job needs (Renwick et al., 2008). This kind of HR practices will assure that candidate attitude attributes, norms, and personality in the direction of reducing waste, perform with innovation and creativity toward the concept of environmental sustainability of their organisation.

\section{Literature Review and Theoretical Framework of GHEM}

The concept of green HRM included all practices ( see Figure 1) lead to reduce the carbon footprints through all HRM practices that include green job design and analysis, green HR Planning, green recruitment and selection, green induction, green training and development, green performance appraisal, green reward, green employee relations...etc (Opata and Arulrajah, 2014). The other dimensions are strategic management and leadership orientation and direction. People are the machine producing sustainability, people are the sponsor to deliver the sustainability practices in their organisation. Green HR is the procedure that environment-friendly concept applying the HR policies which leads to more engagement of employees, cost-effective leadership fostering of orgainsational sustainability rout. Training and development should focus on improving employees' knowledge, experience, skills, attitudes, behaviour, and practices toward the concept of environmental management and green HRM (Shandra Das \& Singh, 2016).

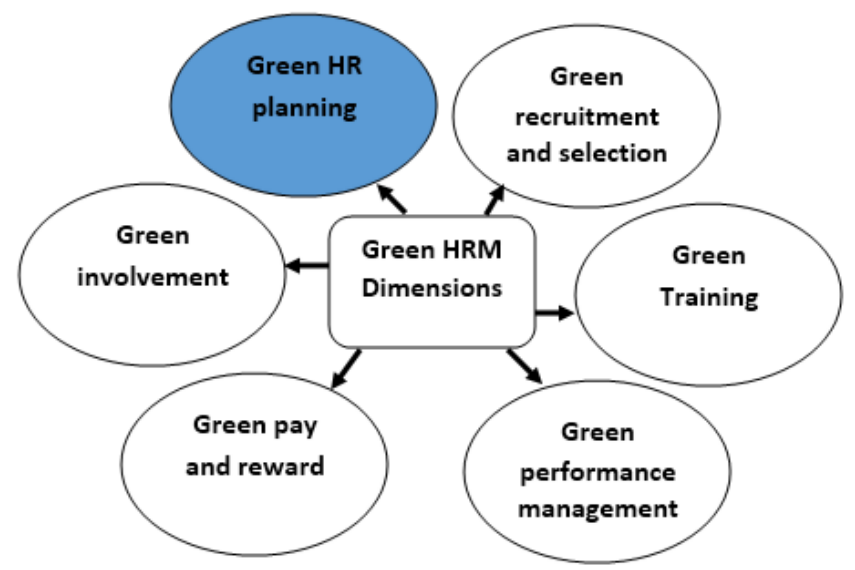


The activity of Green HRM should include but not limited to work practices and process, development, such as how to save energy, engage employees to create different activity for solving environment troubles, reduce waste, that will direct employee to enhance and reinforce their skills, attitude and behaviour toward the sustainability of their organisation (Carter and Dresner, 2001; Shandra Das \& Singh 2016).

\section{HR practices connected to green perspective:}

The concept of GHRM is related to all the activity and practices take part to improve, developing, Implementing and system fixing to develop staff to the level of green and environment Fridley as the approach of working style. (Mehta and Chugan, 2015). GHRM is focused on transforming employee to environmental green friendly, behave and perform in way of contributing to suitability from an environmental perspective. As Deshwal in 2015 mentioned that GHRM is what the policy supports the direction of efficient use of resources for sustainability purposes (Deshwal, 2015). The following explanation will be highlighting and summaries the traditional function of HR that related to the green HRM practices.

Table 1. Definitions and characteristics of HR five dimensions in environmental context, source Tang, et.all (2018)

\begin{tabular}{|c|c|c|}
\hline HRM practices & Definitions and main processes in HRM & Environmental application \\
\hline $\begin{array}{l}\text { Recruitment and selection } \\
\text { (e.g. Jabbour, Santos and } \\
\text { Nagano 2010) }\end{array}$ & $\begin{array}{l}\text { The process in organization to hunt and stimulate potential } \\
\text { candidates to apply for vacancies, which aims at } \\
\text { increasing the quantity of candidates and in turn, } \\
\text { reducing this number through various tests to select the } \\
\text { best candidate meeting the vacancy }\end{array}$ & $\begin{array}{l}\text { The preference of organization is to select candidates } \\
\text { committed and sensitive to environmental issue } \\
\text { and willing to contribution to this through } \\
\text { internal or external recruitment }\end{array}$ \\
\hline $\begin{array}{l}\text { Training } \\
\quad \text { (e.g. Ivancevich 1992) }\end{array}$ & $\begin{array}{l}\text { A series of learning activities, such as skills, knowledge, } \\
\text { provided by organization guides the employees' } \\
\text { behaviors towards organizational objectives }\end{array}$ & $\begin{array}{l}\text { Organization implements a system of learning } \\
\text { practices related to environmental issues in order } \\
\text { to improve employees' aware and skills for } \\
\text { environmental management in job }\end{array}$ \\
\hline $\begin{array}{l}\text { Performance management } \\
\text { (e.g. Jabbour, Santos and } \\
\text { Nagano 2008) }\end{array}$ & $\begin{array}{l}\text { Aiming at general improvement of employees' } \\
\text { performance, organization will compare employees' } \\
\text { results with goals, through which the strategic goals } \\
\text { would be achieved in the long-term }\end{array}$ & $\begin{array}{l}\text { With the vision of environmental management, } \\
\text { organization will appraise employees' } \\
\text { environmental results in the whole process of } \\
\text { operation to judge their contribution to } \\
\text { organizational goals }\end{array}$ \\
\hline $\begin{array}{l}\text { Pay and reward system } \\
\text { (e.g. Jabbour, Santos and } \\
\text { Nagano 2010) }\end{array}$ & $\begin{array}{l}\text { A series of rewarding measures aim at attracting, retaining } \\
\text { and motivating the most fitting employees, in turn, to } \\
\text { encourage relative knowledge, attitudes and behaviors of } \\
\text { members to complete organizational objectives }\end{array}$ & $\begin{array}{l}\text { Financial and non-financial rewards for } \\
\text { organizational members whose attitude or } \\
\text { behavior is conductive to environmental } \\
\text { management }\end{array}$ \\
\hline $\begin{array}{l}\text { Employee involvement } \\
\text { (e.g. Renwick, Redman } \\
\text { and Maguire 2013) }\end{array}$ & $\begin{array}{l}\text { Employees participate in the operational process and } \\
\text { commit to the success of firms, contributing their } \\
\text { various capacities to organizational improvement }\end{array}$ & $\begin{array}{l}\text { An opportunity is provided for employees to engage } \\
\text { in environmental management. The broad types } \\
\text { include participation, support culture and tacit } \\
\text { knowledge, which aim at stimulating member's } \\
\text { commitment to the environmental management } \\
\text { of organization }\end{array}$ \\
\hline
\end{tabular}

Green HR Planning (GHRP): companies are targeted GHR planning are searching for employees have experienced or need to implement initiatives that target corporate environment, activities, projects and programme such as (ISO 14001, Low Carbon Technology (LCT), cleaner production...etc.). Generally, job description and person specification should highlight a number of environmental protection related duties, tasks, specific clear responsibilities, the technical requirement (Renwick et al, 2013). The job description and person specification should include a requirement for environmental, personal, technical criteria for a candidate applying for jobs. (Wehrmeyer, 1996; Renwick et al, 2013).

Green Recruitment and selection: organisations must attract talent with new ideas and perspective (Stringer, 2009). They should have the potential of attracting and hiring an individual with innovative and creative skills has been mentioned (Renwick et al., 2013). The process of recruiting new talent should include those who are familiar with the sustainable environment, in the recruitment we should recruit an individual who has previous experiences and aware of practices with green environment, and they have an initial idea how they will apply this for the organisation recruiting them (Wehrmeyer, 1996). The company applying online recruitment system they apply green recruitment as part of reducing carbon footprint.

As a step after recruitment and selection the write candidate as an employee to the organisation, the company should provide candidate/s with the information required regarding carbon footprint practices show he/she follow, in some organisation, they delivered green indication separated includes the objectives of the origination in 
green environment direction. The induction should be design in a way more engaging and embedding the new employee to the green culture.

Green Training; the HR training and development programme should focus on the significance of reducing threaten to affect the environment and ecological scarcities, this programme should be developed and target all levels of employees. The green training program that which includes all the knowledge, activity and Skills that target to teach employee the way of reducing all waste, a suitable way of using organisation resource, applying Low Carbon Technology energy use and reduce elements that affect the environment negatively and badly. The training also gives an opportunity to the employee to be more engaged in problem-solving related to environment (Zoogah, 2011). A study has been conducted among 437 employees by Similarly Daily et al. in 2007 shows that the development of embedding green management and activity in an organisation directly depends on training on environmental issues. (Daily et al., 2007). The training program should include all activity such as workshops, master class, session, experiential class (simulation) that employee obtained knowledge in environmental management in their organisation, the training and learning programme should target to improve employee knowledge, skills and become an essential part in career progression, so it should be equipped employee as future managers and leaders, applying more online courses and materials essay accessible to all level of employees.

Green Performance management system GPMS): in addition to use the GPMS electronically as one of the greens and clean environment, it is essential to measure the performance of each unit towered environmental performance standard for example 14001 and managers performance(Jackson et al., 2011 ). Setting targeted for managers in their performance regarding environmental management will embedding the culture and will increase the value of environment performance (Renwick et al., 2013). Researcher such as Gill Mandip (2011) acknowledged that GPMS is considered as an effective way of implementation Green performance successfully.

Green Pay and Reward: compensation and reward system is the leverage to force the change in the organisation in the direction of green environmental performance and culture (Mehta and Chugan, 2015). This system should recognize any contributions in the green activity. Tailoring Compensation bundles should be based on green skills. Compensation bundles should be tailored to reward employees' green skills acquisition and tasks achievements (Deshwal, 2015). The compensation system should be considered financial and non-finical recognition. The financial such as salary increase, cash bonuses and intensive, while non-finical based on gifts for employee and their families, holidays and recognition by top management executive and EDO it can have a big impact on employee motivation towered green performance.

Green Involvement: Involvement of employee is to give them the environmental management opportunities to participate with that will encourage them to take over the responsibility to prevent any pollution and identify environmental issues (Renwick, Redman and Maguire 2013). Researches have provided that finding related to green involvement (GI) is very important and fundamental in improving the performance of Environment management (EM) system, for instance reducing waste and pollution in workplaces, and making the best resource management system (Florida and Davison 2001). Another researcher such as Renwick, Redman and Maguire (2013) emphasized a numeral process of employee green involvement. According to Renwick, Redman and Maguire (2013), there are five aspects has been identified for measuring green Involvement (GI) these aspects are: offering green practices; clear green vision, various communication channels, a green learning climate and inspiring green involvement.

\section{Benefits of GHRM:}

There are many reasons for a company to adapt GHRM, the concept has many benefits for the organisation as well as employees. It improves employee morale, attitude and behaviour to save the environment. These benefits listed by Bangwal and Tiwari (2017) as: Improve rate of retention in employee; improved public image; improvement in attracting better employees; improvement in productivity; improvement in sustainable use of resources; reduction of practices that cause the degradation of the environment; save environmental impact; rebates and tax benefits and increase business opportunities.

\section{Challenges facing GHRM}

The concept of GHRM and green staffing is the concept which starts from entry orientation until exit from the organisation, apply green staffing is kind of go green is a global direction. The HR department in any organisation has essential responsibly to shape the policy targeted, direct the employee to the green perspective. The HR policy considered the guidance the way people behavior and managing them in a philosophical way of GHRM and green staffing in their organisation. Literate give some potential for challenges facing GHRM, Deshwal in (2015) pointed out the following challenges. (1) the difficulty of modifying or change employee 
behavior in a short time; (2) there is no grantee that each employee will be motivated equality to the concept of GHRM; (3) to create the culture support GHRM and force to implement can be burdensome and remaining process; (4) recruiting a green talent employee can be a challenging job; (5) measuring the GHRM effectiveness employee behavioral; (6) HR practitioners will be under stress since they are responsible to implement the process of GHRM, selecting the suitable employee and will be expected to achieve it.

\section{Methodology}

\subsection{Objectives of the Study}

- To review different previous study on the concept of GHRM

- To highlight various GHRM initiatives considered by business organisations and firms.

- To identify the theoretical framework for GHRM and its practices

- To test the perspective of GHRM in the contraction companies in Egypt and the UK

- To identify the challenges facing GHRM practices

- To recommended themes for further research

\subsection{Sample and Procedure}

This study targeted HR representatives and manager working in private construction companies in Egypt and the UK. 5 companies were in the UK and 10 companies in Egypt. Only 40 employees fill the survey in the UK and 152 employees fill the survey in Egypt. A sample size of 300 is expected to be representative, Only 192 responded positively responds. Participants were approached in their offices and were asked to complete the survey after assuring that their participation was voluntary and anonymity was guaranteed. With a response rate $(66.7 \%)$ of respondents were male. $(33.3 \%)$ of the respondents were female.

These characteristics indicate a reasonable mix of demographic groups represented in the collected data.

Diagram (2) sample distribution on the level of country and gender
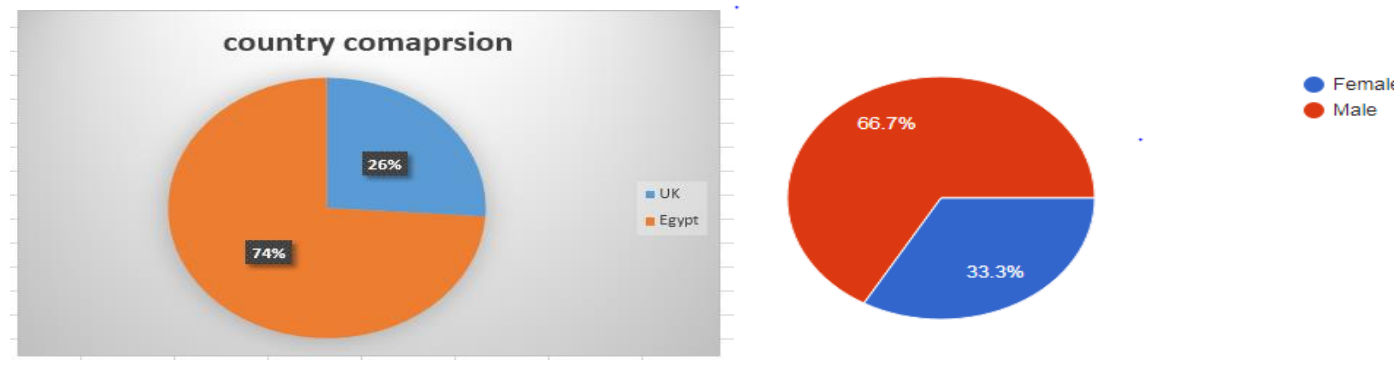

\subsection{Measures}

First reviewing publication target the concept of GHRM. And to design a clear theoretical framework for the GHRM.

Second, to test the perspective of employees working in construction companies. Two-part was used to assess the study variable which the perspective of employees in construction companies in Egypt and the UK. GHRM was measured using 19 items scale developed by Chen, et, all. (2018) to assess Green Recruitment and selection (GRS); Green Training (GT); Green Performance Management (GPM); Green pay and reward (GPR); Green involvement GI). Finally, demographic variables including gender, country, and department, and experience were also assessed. 


\section{Result and discussion:}

Table 2. HR practices in Egypt

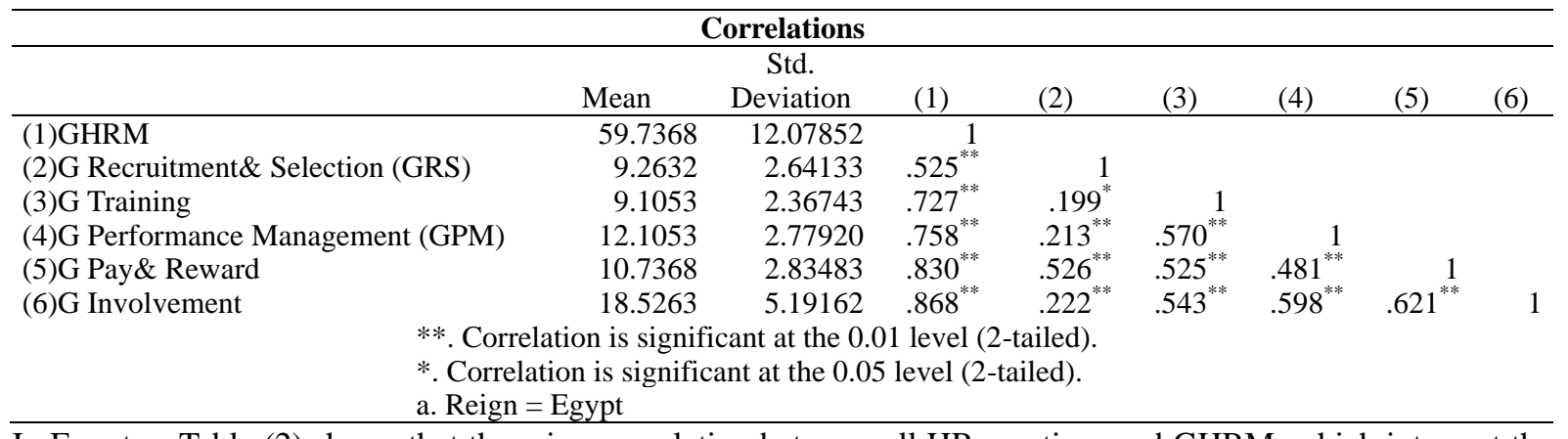

In Egypt as Table (2) shows that there is a correlation between all HR practices and GHRM, which interpret the GHRM is considered as a package and should to apply for all the HR practices to develop the perspective of GHRM. Also, the study reported that the high correlation in the main Green HR practices indicates that the employee in these companies taking green Initiative and provide a green workplace for a healthy and satisfactory outcome and creating a sense of responsibility among employees towards the environment. The most important thing in the perspective, that employee is ready to take and apply any initiatives for GHRM, then it's the company responsibility to imbedding GHRM activity in their strategies, policy, and practices.

Table 3. HR practices in the UK

\begin{tabular}{|c|c|c|c|c|c|c|c|c|}
\hline \multicolumn{9}{|c|}{ Correlations } \\
\hline & Mean & Std. Deviation & (1) & $(2)$ & (3) & (4) & (5) & (6) \\
\hline (1)GHRM & 58.2000 & 17.17959 & 1 & & & & & \\
\hline (2)G Recruitment\& Selection (GRS) & 8.4000 & 3.42540 & $.964^{* *}$ & 1 & & & & \\
\hline (3)G Training & 8.8000 & 3.22808 & $.766^{* *}$ & $.879^{* *}$ & 1 & & & \\
\hline $\begin{array}{l}\text { (4)G Performance Management } \\
(\mathrm{GPM})\end{array}$ & 12.4000 & 3.65710 & $.632^{* *}$ & $.413^{* *}$ & .024 & 1 & & \\
\hline $\begin{array}{l}\text { (5)G Pay \& Reward } \\
\text { (6)G Inyolyement }\end{array}$ & $\begin{array}{r}9.8000 \\
18.8000\end{array}$ & $\begin{array}{l}4.17072 \\
8.28715\end{array}$ & $.416^{* *}$ & .264 & -.171 & $\begin{array}{r}.812^{* *} \\
280\end{array}$ & $\begin{array}{r}1 \\
-043\end{array}$ & 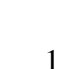 \\
\hline
\end{tabular}

**. Correlation is significant at the 0.01 level (2-tailed). a. Reign = UK

The statistic report that, as the table (3) shows that in the UK the perspective of the employee is higher than Egypt. There are correlations between all the GHRM practices. However in the pay and reward not correlated to GHRM practices which is totally different in Egypt. The statistic reported that the two countries and their construction sector are really for GHRM applications and practices. So the messages to the rest of the companies to start their intuitiveness to spired the GHRM in these companies.

\section{Implication on the Theoretical Level and Practical Level}

Targeted Candidates should be selected based on organisation green criteria, which has been set from the beginning during HR planning. It has been mentioned that candidates will be attracted to organisation green image (Behrend, Baker and Thompson 2009). Also, companies with environmental orientation are likely to recruit candidates possessing environmental knowledge recruit candidates possessing environmental knowledge and highly encouraged to take part in the environment activities (Guerci, Longoni and Luzzini 2016).

The result of this study model shows that such HR planning is required in the theoretical formwork of the GHRM, since many studies focus only of the other practices but not mentioned the HR planning as a main element. GHRM is considered as one of the most important dimensions of HRM, that highlighting the role of considering the green staffing from the beginning different researcher have liked HR planning and Green involvement to environment strategies as one of the challenges facing many companies nowadays (Jabbour, Santos and Nago, 2008; Haddockmillar, Sanyal and Mullercamen,2016).

The concept of GHRM is a relatively new concept to be searched. Few researchers targeted to review the topic from a theoretical background, however, there is still there is a lack of clear inclusive GHRM framework. The literature shows there are several gaps need to be covered in respect of GHRM. Examples of this gap are a clear guide to the way implementing based on cumulative literature review and its link to the international regulation, 
logical framework presents the dimensions and process of the application of GHRM can be used in future research to be tested in the HR field. The future empirical studies are needed to present an improved framework for GHRM, there is a much of quantitative and qualitative research need in the field of GHRM.

While Lado and Wilson in 2014 explain GHRM that interrelated activities, process, function which direct employee to talent management combining of attracting, developing and retain within the organisation. GHRM function is the framework of HR activity which adapts many green practices and process that reflect on the carbon footprint of their company (Prasad, 2013).

Regarding the practical implications, the main finding of this study might horizons of managers perspective. In the process of EM (environment management) manager should take into consideration all the dimensions of GHRM practices mentioned and tested in this study when they recruiting new employees are more aware and sensitive to environment and have clear vision and perspective with values. Also, evaluation employee performance by taking into consideration their green behaviour is very crucial as it is associated with the environmental performance of employees (Guerci, Longoni and Luzzini 2016). The employee should be motivated and involved in the environmental decision- making tasks and activities, encourage them to join any further learning and training opportunities improve their knowledge, raise their awareness about the environment.

\section{Conclusion Future Research Agenda}

Green staffing and GHRM are an innovative phenomenon in the HRM field. The concept GHRM has massive power in influencing HRM functions and process in green staffing, employee behavior, orgainsational operation, and strategic management. In the HRM dimensions applying GHRM start from HR planning, job analysis, and job design until the employee relations and strategic HRM. The main key challenge facing HR practitioners is a deep understanding of GHRM and how it should be applying in real life and transform their firms into green bodies. This potential effort eventually leads firms to better environmental performance. This attempted study tried to investigate the GHRM and green staffing concepts, requirements, benefits, processes, and challenges facing HR practitioners and management applying in their organisations. This study discovered that GHRM can implement numerous GHRM practices from the perspective of operation and processes such as the acquisition of human capital, HR planning, recruitment and selection, training and development, Performance management system (PMS), compensation and benefits and Strategic HRM that all will lead to orgainsational goal achievement. The function of HRM acts as a driver of sustainability throughout embedding green HRM policies and practices with the strategic objectives of each organisations (Cherian and Mandip, 2012; Jacob, 2012). The main findings of the study are the association of clear HR policy, strategic management, tope management, leadership and leader's behavior, green awareness raising, teamwork, enabling with the empowerment of employee will. Although HR practitioners facing many challenges as a new perspective, However, the study shows that HR practitioners must highlight the environmental requirements while manufacturing HR strategies ( analysis, formulation, and implementation) in combining with HR policies in arrangement with environmental management. The propose of this study is to help scholars, researcher and a cadmic to recognize the areas of GHRM that need to be highlighted for the purposes of study and investigated. Thus, further research should consider in continue to investigate and test the GHRM, EM and other dimensions related to the GHRM practices in other sectors.

\section{References}

Aravamudhan, N. R. (2012). Green HR getting into the business of green. HRM Review. 12, 31-40. ISSN: $1053-4822$.

Bangwal \& Tiwari (2017). Green HRM, Work-life and Environment performance. International Journal of Environment, Workplace and Employment, 4(3), 244-268. https://doi.org/10.1504/IJEWE.2017.087808

Behrend, T. S., B. A. Baker, \& L. F. Thompson, (2009). Effects of pro-environmental recruiting messages: the role of organizational reputation. Journal of Business and Psychology, 24(3), 341-35. https://doi.org/10.1007/s10869-009-9112-6

Carter, C., \& Dressner, M. (2001). Purchasing role in environment management: Cross Functional development of Grounded theory. Journal of Supply Chain Management, 12-27. https://doi.org/10.1111/j.1745-493X.2001.tb00102.x

Chesbrough, H. W. (2003). Open Innovation: The New Imperative for Creating and Profiting from Technology, Harvard Business School Press, and Boston.

Daily, B. F., \& Huang, S. C. (2007). Achieving sustainability through attention to human resource factors in 
environmental management. International Journal of Operations \& Production Management, 21(12), 1539-1552. https://doi.org/10.1108/01443570110410892

Deshwal, P. (2015). Green HRM: An organizational strategy of greening people. International Journal of Applied Research, 1(13), 176-181. ISSN Online: 2394-5869

Gill, M. (2011). Green HRM: People Management Commitment to Environment Sustainability. Research Journal of recent Science, 244-254.

Govindarajulu, N., \& Daily, B. F. (2004). Motivating Employees for Environmental improvement. Industrial Management and Data Systems, 104, 364-372. https://doi.org/10.1108/02635570410530775

Guerci, M., A. Longoni, \& D. Luzzini, (2016) Translating stakeholder pressures into environmental performance: the mediating role of green HRM practices. International Journal of Human Resource Management, 27(2), 262-289. https://doi.org/10.1080/09585192.2015.1065431

Haddockmillar, J., C. Sanyal, \& M. Mullercamen, (2016) Green human resource management: a comparative qualitative case study of a United States multinational corporation. International Journal of Human Resource Management, 27(2), 192-211. https://doi.org/10.1080/09585192.2015.1052087

Jabbour, C. J. C., F. C. A. Santos, \& M. S. Nagano, (2008) Environmental management system and human resource practices: is there a link between them in four Brazilian companies? Journal of Cleaner Production 16(17), 1922-1925. https://doi.org/10.1016/j.jclepro.2008.02.004

Jabbour, C. J. C., F. C. A. Santos, \& M. S. Nagano, (2010). Contributions of HRM throughout the stages of environmental management: methodological triangulation applied to companies in Brazil. International Journal of Human Resource Management, 21(7), 1049-1089. https://doi.org/10.1080/09585191003783512

Jackson, S. E., Renwick, D. W. S., Jabbour C. J. C., \& Camen, M. M. (2011). State-of-the-Art and Future Directions for Green Human Resource Management: Introduction to the Special Issue. German Journal of Research in Human Resource Management, 25(2), 99-116.

Justin, V. (2008), Green workplace, SHRM Survey, 1-6

Lado, A. A., \& Wilson, M. C. (1994). Human resource systems and sustained competitive advantage: A competency-based perspective. Academy of Management Review, 19(4), 699-727. https://doi.org/10.5465/amr.1994.9412190216

Lee, K. H. (2009). Why and how to adopt green management into business organizations: the case Study of Korean SMEs in manufacturing industry'. Management Decision, 47(7), 1101-1121. https://doi.org/10.1108/00251740910978322

Mehta, K., \& Chugan, P. K. (2015). Green HRM in pursuit of environmentally sustainable business. Univers. J. Ind. Bus. Manag. 3, 74e81.

Müller-Camen, M.; Haddock-Millar, J., \&Sanyal, C., (2016). Green human resource management: a comparative qualitative case study of a United States multinational corporation. The International Journal of Human Resource Management, 27(2), 192-211. https://doi.org/10.1080/09585192.2015.1052087

Nijhawan, G. (2014). Green HRM - a requirement for sustainable Environment. Pariplex-Indian Journal of Research, 3(10). Ford (2012). http://corporate.ford.com/doc/corpgov_sustainability_committee_charter.pdf

Opatha, H. H., \& Arulrajah, A. A., (2014). Green Human Resource Management: simplified general reflections. International Business Research, 7, 101-112. https://doi.org/10.5539/ibr.v7n8p101

Prasad, R. (2013) Green HRM - Partner in Sustainable Competitive Growth. Journal of Management Sciences and Technology, 1(1).

Renwick, D. E., Redman, T., \& Maguire, S. (2013). Green human resource management: a review and research agenda. International Journal of Management Reviews, 15, 1-14. https://doi.org/10.1111/j.1468-2370.2011.00328.x

Renwick, D., Redman, T., \& Maquire, S. (2008). Green HRM: A Review, Process Model, a Research Agenda, Discussion Paper Series. University of Sheffield Management School, the University of Sheffield.

Renwick, D., Redman, T., \& Maquire, S. (2008). Green HRM: A Review, Process Model, a Research Agenda, Discussion Paper Series. University of Sheffield Management School, the University of Sheffield.

Shandra Das, S., \& Singh, R. (2016). Green HRM and Orgainsational suitability: An Empirical Review. Kegees Journal of Social Science, 8, 227-236. 
Sharma, N., \& Gupta, N. (2009). Green HRM: An Innovative approach to environmental sustainability. Society for human resource management, Green workplace: survey brief.

Stringer, L. (2009). The Green workplace. Sustainable strategies that benefit employees, the environment, and the bottom line. New York, NY: Macmillan.

Wherever, W. (1996). Introduction in greening people: Human Resource and Environment Management, 15, Greenfield publishing Sheffield.

Zoogah, D. (2010). The Dynamics of Green HRM Behaviors: A Cognitive Social Information Processing Approach. Working Paper, Morgan State University, Baltimore Maryland, USA, 2010.

\section{Copyrights}

Copyright for this article is retained by the author(s), with first publication rights granted to the journal.

This is an open-access article distributed under the terms and conditions of the Creative Commons Attribution license (http://creativecommons.org/licenses/by/4.0/). 